\title{
1. Prevention is better than cure
}

If you are thinking a year ahead - plant seeds.

If you are thinking 10 years ahead - plant a tree.

If you are thinking 100 years ahead - educate the people. ${ }^{1}$

\subsection{INTRODUCTION}

The medical profession has long recognized that 'prevention is better than cure', as reflected in the development of vaccinations for a wide range of diseases, and the advocating of a healthy diet and exercise as one of the best ways of preventing diabetes and coronary problems. Much money is spent on medical research into prophylactic treatments designed to fend off disease, and as a result there have been significant breakthroughs, for example, ciprofloxacin for persons who may have been exposed to anthrax ${ }^{2}$ and chloroquine for those going into malaria-prone areas. ${ }^{3}$ Similarly, doctors and governments recognize that it is much cheaper and easier to prevent people smoking than to treat lung cancer, and as a result invest significant sums in programmes designed to help people quit smoking. ${ }^{4}$

It seems that the United Nations (UN) similarly recognized that prevention is better than cure when it advocated, over 60 years ago, that 'Education shall be directed to ... the strengthening of respect for human rights' ${ }^{5}$ The founders of the UN realized that it is far better to prevent human rights abuses occurring than to try and 'cure' the problem, for example, by sending in peacekeepers after human rights atrocities have been committed.

\footnotetext{
1 Kuan-Tzu (fourth to third century BC), China.

2 See Food and Drug Administration, US Department of Health and Human Services, 'Approval of Cipro ${ }^{\circledR}$ for use After Exposure to Inhalational Anthrax', 31 August 2000. Accessed at http://www.fda.gov/bbs/topics/answers/ans01030.html, 4 May 2009.

3 See www.traveldoctor.co.uk/tables.htm, accessed 4 May 2009.

4 See for example, 'Quit Victoria' (www.quit.org.au), a joint initiative of the Cancer Council Victoria, the Department of Human Services, the National Heart Foundation and Vic Health.

5 Universal Declaration of Human Rights, General Assembly Resolution 217 A (III), 10 December 1948, Article 26(2).
} 
Unfortunately, the lofty ideals of the drafters of the Universal Declaration of Human Rights (UDHR), that human rights education (HRE) could help prevent massive human rights violations, like the Holocaust they had just witnessed, have not become reality. Notwithstanding that it has been more than six decades since the concept of HRE first entered the lexicon of international law, it is readily apparent that HRE has not succeeded in preventing widespread human rights abuses. Words like 'Rwanda', 'Srebrenica' and 'Darfur' immediately bring to mind examples of our failure to prevent catastrophic human rights violations, and a cursory glance at any newspaper reveals smaller-scale human rights abuses occurring around the world on a daily basis. Thus, it appears that the UN's attempts to use prophylactic measures to combat human rights violations have not been as successful as the medical profession's use of prophylactics to combat diseases.

This book analyses the role the UN has played in promoting HRE as a preventative tool. The UN is a complex organization comprising a multitude of different organs. The UN Charter ${ }^{6}$ established six principal organs, namely: the General Assembly, the Security Council, the Economic and Social Council, the Trusteeship Council, the International Court of Justice and the Secretariat. Beneath these six organs sit a number of subsidiary bodies to whom various functions are delegated, including, for example, the Human Rights Council (subsidiary to the General Assembly) and the Office of the High Commission for Human Rights (Department of the Secretariat).

In addition to these Charter-based bodies, there are expert committees created by various human rights treaties to monitor compliance with specific treaties. Currently, there are nine such treaty bodies ${ }^{7}$ charged with overseeing the implementation of the core human rights treaties. ${ }^{8}$

6 Adopted on 26 June 1945, in San Francisco, and entered into force on 24 October 1945.

7 Human Rights Committee, Committee on Economic, Social and Cultural Rights, Committee on the Elimination of Racial Discrimination, Committee on the Elimination of Discrimination Against Women, Committee Against Torture, Committee on the Rights of the Child, Committee on Migrant Workers, Committee on the Rights of Persons with Disabilities and Committee on Enforced Disappearances.

8 International Covenant on Civil and Political Rights, International Covenant on Economic, Social and Cultural Rights, International Convention on the Elimination of All Forms of Racial Discrimination, Convention on the Elimination of All Forms of Discrimination against Women, Convention against Torture and Other Cruel, Inhuman or Degrading Treatment or Punishment, Convention on the Rights of the Child, International Convention on the Protection of the Rights of All Migrant Workers and Members of Their Families, Convention on the Rights of Persons with Disabilities and International Convention for the Protection of All Persons from Enforced Disappearance. 
This book offers a microanalysis of the way in which six distinct UN structures are seeking to promote HRE. In particular, it maps the UN's HRE activities and approaches within the following entities:

- Committee on Economic, Social and Cultural Rights (CESC);

- Committee on the Rights of the Child (CRC);

- Human Rights Council (HRC);

- Economic and Social Council (ECOSOC);

- General Assembly (GA); and

- Office of the High Commission for Human Rights (OHCHR).

These organs of the UN were carefully selected so as to paint a comprehensive picture of the nature and extent of promotion of HRE within the UN. Thus, the organs chosen include bodies made up of independent experts (CESC and CRC), governmental representatives (HRC, ECOSOC and GA) and UN staff (OHCHR). All these entities have specific obligations regarding HRE, and provide a useful means of comparing the approaches taken by a UN body comprising human rights experts, a political body made up of government representatives and a body consisting of UN bureaucrats. It provides a unique opportunity to expose any dissonance between the HRE interpretations and activities of different UN entities - expert, inter-governmental and bureaucratic. If different human rights bodies within the UN are adopting inconsistent or conflicting approaches to the realization of HRE, this may shed light on why the UN has not been successful in promoting HRE as a preventative human rights tool. Thus, this book represents the first piece of scholarship to adopt a formal, systematic and analytical approach to the UN's HRE activities and provides new insight into the UN's role in advancing education about human rights.

Before evaluating the role the UN has played in promoting HRE, it is important to analyse why the UN considers HRE to be important and what role the UN sees HRE playing in the prevention of human rights abuses. What is the UN's vision for HRE, and what does it hope to achieve by the various initiatives it has embarked upon over the past few decades?

Answering these questions provides a framework for analysing the UN's HRE efforts. Knowing and understanding the UN's motivation and philosophy regarding HRE provides both context and meaning for this research. The answers to these questions are, in effect, the skeleton upon which the meat of this research is attached, and this chapter seeks to expose that skeleton. 


\subsection{THE UN AND HUMAN RIGHTS}

Before beginning to analyse the role the UN has played in promoting HRE, it is important to understand the relationship between the UN and human rights more broadly. From the moment the UN was established in 1945, human rights featured as part of its responsibilities. In particular, Article 1 of the UN Charter provides that one of the purposes of this new organization is to promote and encourage 'respect for human rights and for fundamental freedoms'. ${ }^{9}$ This is reiterated in Article 55, which refers to the UN promoting 'universal respect for, and observance of, human rights and fundamental freedoms'. Thus, it is clear that from the outset the promotion of human rights was to be a core part of the UN's functions and responsibilities.

The UN's effort to promote human rights has taken many forms including:

1. standard setting, through the creation of human rights treaties;

2. monitoring and supervising the implementation of human rights; and

3. enforcing compliance with human rights, including, for example, the imposition of sanctions by the Security Council. ${ }^{10}$

The UN has received much praise for its standard-setting endeavours, and much criticism for its weak enforcement mechanisms. ${ }^{11}$ However, there has been insufficient scholarly analysis of the work of UN bodies to monitor and supervise the implementation of human rights. This book seeks to fill that gap by providing a microanalysis of the work of six UN entities when it comes to monitoring and supervising states' efforts to comply with international norms relating to HRE.

In 1948, the General Assembly of the United Nations adopted the Universal Declaration of Human Rights. This Declaration, for the first time in history, detailed a set of basic and fundamental human rights which all human beings are entitled to enjoy. The adoption of this document spurred the international movement for human rights. As this movement has grown and evolved, so have the human rights activities of the United Nations. In the standard setting arena, the UN's human rights work can be seen in the development of nine core human rights instruments, namely:

9 UN Charter. Accessed at www.un.org/en/documents/charter/index.shtml, 8 September 2012.

10 Joseph, Sarah and Kyriakakis, Joanna, 'The United Nations and Human Rights' in Joseph, Sarah and McBeth, Adam (eds) Research Handbook on International Human Rights Law (2010), Edward Elgar, Cheltenham.

11 Ibid. 
- International Covenant on Civil and Political Rights (ICCPR);

- International Covenant on Economic, Social and Cultural Rights (ICESCR);

- International Convention on the Elimination of All Forms of Racial Discrimination (CERD);

- Convention on the Elimination of All Forms of Discrimination against Women (CEDAW);

- Convention against Torture and Other Cruel, Inhuman or Degrading Treatment or Punishment (CAT);

- Convention on the Rights of the Child (CROC);

- International Convention on the Protection of the Rights of All Migrant Workers and Members of Their Families;

- International Convention for the Protection of All Persons from Enforced Disappearance; and

- Convention on the Rights of Persons with Disabilities.

In addition to these nine core human rights treaties, there are a number of optional protocols that extend the obligations in some of these treaties, including, for example, the Second Optional Protocol to the International Covenant on Civil and Political Rights, aimed at the abolition of the death penalty, the Optional Protocol to the Convention on the Rights of the Child on the involvement of children in armed conflict, and the Optional Protocol to the Convention on the Rights of the Child on the sale of children, child prostitution and child pornography.

Human rights standards are also contained in a variety of soft law provisions, including the Vienna Declaration and Programme of Action and the United Nations Millennium Declaration. Thus, there is no shortage of UN documentation setting out the human rights standards by which the world is expected to live. The extent to which HRE is articulated in both these hard law and soft law instruments forms the basis of this research.

As noted above, in addition to standard setting, the UN also plays a role in enforcement of human rights standards. One way it endeavours to do this is via the mechanism known as 'individual communications'. This process enables a person to make a complaint to select UN treaty committees, alleging that one or more rights contained in a treaty have been violated. According to the Office of the High Commissioner for Human Rights, 'the ability of individuals to complain about the violation of their rights in an international arena brings real meaning to the rights contained in the human rights treaties'. ${ }^{12}$

12 Accessed at http://www2.ohchr.org/english/bodies/petitions/index.htm, 8 September 2012. 
There is no record of a complaint ever having been brought to a treaty committee alleging breach of a right to human rights education. However, the development of optional protocols, allowing individual complaints to be brought to the Committee on Economic, Social and Cultural Rights, ${ }^{13}$ and the Committee on the Rights of the Child ${ }^{14}$ pave the way for future individual communications to the UN regarding an alleged violation of the HRE provisions of ICESCR (Article 13) and CROC (Article 29). Once these optional protocols enter into force, individual communications to UN treaty committees may become a viable means of increasing compliance with the HRE provisions contained in human rights treaties.

\subsection{THE UN'S VIEW OF HRE AS A TOOL FOR PREVENTING HUMAN RIGHTS ABUSES}

There is an inextricable link between HRE and the realization of human rights. As one notable human rights education expert described it, HRE is about 'empowering the individual to both recognize human rights abuses and to commit to their prevention'. 15 Thus, a core part of HRE is the strengthening of respect for human rights. ${ }^{16}$

There are a number of UN documents that shed light on the UN's vision for HRE. The four most significant ones are analysed in this chapter, namely:

- General Comment No. $1^{17}$ on the aims of education published by the Committee on the Rights of the Child;

- Plan of Action for the UN Decade for Human Rights Education; ${ }^{18}$

- Plan of Action for the First Phase (2005-2009) of the World Programme for Human Rights Education; ${ }^{19}$ and

13 An Optional Protocol to ICESCR providing for individual communications to the Committee was adopted by General Assembly by Resolution A/Res./63/117 on 10 December 2008. It will enter into force three months after the tenth ratification (Article 18).

14 An Optional Protocol to CROC providing for individual communications to the Committee on the Rights of the Child was adopted by the General Assembly by Resolution A/Res./66/138 on 19 December 2011. It will enter into force three months after the tenth ratification.

15 Tibbitts, Felisa, 'Understanding What We Do: Emerging Models for Human Rights Education' (2002) 48(3-4) International Review of Education 159, 166.

16 Plan of Action for the United Nations Decade for Human Rights Education (1995-2004), Appendix to A/51/506/Add. 1, 12 December 1996.

17 CRC/GC/2001/1, 17 April 2001.

18 Appendix to A/51/506/Add. 1, 12 December 1996.

19 A/59/525/Rev. 1, 2 March 2005. 
- Plan of Action for the Second Phase (2010-2014) of the World Programme for Human Rights Education. ${ }^{20}$

The UN's vision for HRE is also exposed through an examination of how HRE came to be incorporated into various human rights instruments, and this analysis is the subject of the next chapter, which explores the provenance of HRE in international law.

\subsubsection{General Comment No. 1 from the Committee on the Rights of the Child}

Human rights treaty bodies within the UN publish their opinions on the content of human rights treaties in the form of General Comments. These General Comments 'provide persuasive interpretations of the treaty provisions" ${ }^{21}$ and have been referred to as being 'distinct juridical instruments, 22 similar to 'advisory opinions' of international tribunals. ${ }^{23}$ Thus, General Comments expose the thinking of the expert bodies on specific issues.

The first General Comment produced by the CRC is titled The Aims of Education, ${ }^{24}$ and sheds light on how this body sees HRE as a tool for preventing human rights abuses. It seeks to unpack the content of Article 29(1) of the Convention on the Rights of the Child, which provides that:

States Parties agree that the education of the child shall be directed to:

(a) The development of the child's personality, talents and mental and physical abilities to their fullest potential;

(b) The development of respect for human rights and fundamental freedoms, and for the principles enshrined in the Charter of the United Nations;

(c) The development of respect for the child's parents, his or her own cultural identity, language and values, for the national values of the country in which the child is living, the country from which he or she may originate, and for civilizations different from his or her own;

(d) The preparation of the child for responsible life in a free society, in the spirit of understanding, peace, tolerance, equality of sexes, and friendship among all peoples, ethnic, national and religious groups and persons of indigenous origin;

(e) The development of respect for the natural environment.

20 A/HRC/15/28, 27 July 2010.

21 Ibid., 13.

22 Buergenthal, Thomas quoted in Steiner, Henry J. and Alston, Philip, International Human Rights in Context: Law, Politics, Morals (2nd edn, 2000), Oxford University Press, Oxford, 732.

23 Ibid.

24 General Comment No. 1, CRC/GC/2001/1, 17 April 2001. 
There are several aspects of General Comment No. 1 that highlight the preventative aims of HRE. For example the CRC observed that:

Racism and related phenomena thrive where there is ignorance, unfounded fears of racial, ethnic, religious, cultural and linguistic or other forms of difference, the exploitation of prejudices, or the teaching or dissemination of distorted values. A reliable and enduring antidote to all of these failings is the provision of education which promotes an understanding and appreciation of the values reflected in article 29 (1), including respect for differences, and challenges all aspects of discrimination and prejudice. ... Such teaching can effectively contribute to the prevention and elimination of racism, ethnic discrimination, xenophobia and related intolerance. ${ }^{25}$ [Emphases added.]

Similarly, there are references to the need for children to learn life skills that enable them to resolve conflicts in a non-violent manner, ${ }^{26}$ and to educational programmes being used as tools to prevent violence and conflict. ${ }^{27}$ In addition, General Comment No. 1 refers to children learning to respect difference and the importance of promoting a culture that is infused by appropriate human rights values. ${ }^{28}$ Thus, HRE is seen as playing a prophylactic role: sowing the seeds of harmonious relationships among all people, thereby helping to prevent the outbreak of violent conflicts and related human rights violations. ${ }^{29}$

Although much of General Comment No.1 is devoted to how to implement Article 29(1) of CROC, rather than the rationale for the norm, it nevertheless helps to elucidate the meaning of Article 29(1) to expose why HRE is perceived as important by the UN, and to shed light on the purpose of a mandate for HRE.

\subsubsection{Plan of Action for the UN Decade for Human Rights Education}

The 1993 World Conference on Human Rights resulted in the Vienna Declaration and Programme of Action (Vienna Declaration), the purpose of which was to create a framework to facilitate the achievement of "substantial progress in human rights endeavours by an increased and sustained effort of international cooperation and solidarity' ${ }^{30}$ One of the outcomes of the World

\footnotetext{
25 Paragraph 11.

26 Paragraph 9.

27 Paragraph 16.

28 Paragraph 2.

29 Baxi, Upendra, 'Human Rights Education: The Promise of the Third Millennium?' in Andreopoulos, George J. and Claude, Richard Pierre (eds) Human Rights Education for the Twenty-First Century (1997), University of Pennsylvania Press, Philadelphia, PA, 146.

30 Vienna Declaration and Programme of Action, A/CONF.157/23, 12 July 1993,
} Preamble. 
Conference was a recognition that HRE is 'essential for the promotion and achievement of stable and harmonious relations among communities and for fostering mutual understanding, tolerance and peace'. ${ }^{31}$ The Vienna Declaration includes a recommendation that the General Assembly consider proclaiming a 'United Nations decade for human rights education in order to promote, encourage and focus these educational activities'. ${ }^{32}$

In due course, the General Assembly proclaimed such a Decade, ${ }^{33}$ pursuant to which the High Commissioner for Human Rights prepared a Plan of Action for its implementation. ${ }^{34}$ This Plan of Action provides another window into how the UN perceives HRE as a preventive tool.

The Plan of Action is predominantly about the ways that HRE can be promoted at the international, regional, state and local levels, but it also sets out that HRE is:

aimed at the building of a universal culture of human rights through the imparting of knowledge and skills and the moulding of attitudes and directed to:

(a) The strengthening of respect for human rights and fundamental freedoms;

(b) The full development of the human personality and the sense of its dignity;

(c) The promotion of understanding, tolerance, gender equality and friendship among all nations, indigenous peoples and racial, national, ethnic, religious and linguistic groups;

(d) The enabling of all persons to participate effectively in a free society;

(e) The furtherance of the activities of the United Nations for the maintenance of peace. $^{35}$

Although there is no specific mention of HRE as a preventive tool, the references to strengthening respect for human rights and maintaining peace go hand in hand with the idea of HRE as a means of preventing human rights abuses, that is, where there is peace and a culture of human rights, there is less likelihood of human rights violations. Although the role of HRE as a preventive tool is implicit in the Plan of Action, it would have been preferable for the Plan of Action to make explicit mention of this. The failure to expressly refer to the link between HRE and the prevention of human rights violations arguably weakens the Plan of Action.

Another omission of the Plan of Action is its failure to make any reference to General Comment No. 1 on HRE published by the CRC a few years earlier.

\footnotetext{
$31 \quad$ Ibid., paragraph 78.

32 Ibid., paragraph 82.

33 Resolution 49/184, 23 December 1994.

34 Appendix to A/51/506/Add. 1, 12 December 1996.

35 Ibid., paragraph 2.
} 
Although the Plan of Action makes fleeting mention of Article 29 of CROC, ${ }^{36}$ the absence of any reference to General Comment No. 1, which is, by any measure, a significant pronouncement on HRE, is unfortunate, and suggests a lack of coordination and collaboration between the different bodies working on HRE within the UN. Making express links to the assorted HRE efforts taking place within the UN demonstrates an interconnectedness that reinforces each of the initiatives and would strengthen the UN's overall HRE message.

\subsubsection{Plan of Action for the First Phase of the World Programme for HRE}

When the UN Decade for HRE came to an end in late 2004, the General Assembly decided that the efforts to promote HRE needed to continue, and therefore adopted the World Programme for Human Rights Education (2005-ongoing) (World Programme) as the vehicle through which to continue the focus on HRE. ${ }^{37}$ The World Programme operates in phases, with each phase concentrating on a different aspect of HRE. The first phase, from 2005 to 2009, was directed at HRE in primary and secondary schools. ${ }^{38}$ The Plan of Action for the First Phase (First Phase Plan) was prepared by the Office of the High Commissioner for Human Rights, and transmitted by the SecretaryGeneral to the General Assembly. ${ }^{39}$

Unlike the Plan of Action for the Decade, the First Phase Plan explicitly comments on the preventive role that HRE performs. Indeed, it is noted in the very first paragraph that HRE 'contributes to the long-term prevention of human rights abuses and violent conflicts', and later there is reference to one of the benefits of HRE being 'social cohesion and conflict prevention'. ${ }^{40}$ Thus, the prophylactic function of HRE is explicitly recognized and commended in the First Phase Plan.

Again, in contrast to the Plan of Action for the Decade, the First Phase Plan makes specific reference to General Comment No. 1 from the $\mathrm{CRC},{ }^{41}$ and quotes with approval various aspects of that document. ${ }^{42}$ It is perhaps not surprising that the First Phase Plan draws so heavily on General Comment No. 1, since both

\footnotetext{
36 Paragraph 1.

37 Resolution 59/113 of 10 December 2004.

38 Initially, the first phase ran from 2005 to 2007 , but this was subsequently extended to 2005 to 2009. see Human Rights Council Resolution 6/24, 28 September

39 Plan of Action for the First Phase (2005-2007) of the World Programme for Human Rights Education, A/59/525/Rev. 1, 2 March 2005.

40 Ibid., paragraph 19.

41 It is referred to six times. See paragraphs 10, 15 and 16 and endnotes 3, 5 and 6.

42 See endnotes 3,5 and 6.
} 2007. 
relate to the education of children about human rights. Nevertheless, the effort to connect these two instruments concerning HRE is commendable, and the two documents reinforce each other to create a consistent and unified approach to HRE.

\subsubsection{Plan of Action for the Second Phase of the World Programme for HRE}

The First Phase of the World Programme for HRE was followed by the Second Phase, which focuses on human rights education for higher education and on human rights training for teachers and educators, civil servants, law enforcement officials and military personnel. This is quite a diverse range of targets for HRE in the Second Phase of the World Programme, and it is clear that the HRE needs of these various sectors will be quite different. This is recognized in the Plan of Action for this Second Phase (Second Phase Plan), ${ }^{43}$ which notes, for example, that law enforcement officials should receive education about the effective prevention and investigation of extra-legal, arbitrary and summary executions. ${ }^{44}$ Unfortunately, this is the only example in the Second Phase Plan that identifies specific preventive aspects of HRE for one of the targeted sectors. It would have been helpful for similar examples to have been included for the other sectors, for example, the military and civil servants.

The Second Phase Plan does, however, highlight the connection between HRE and the prevention of future human rights violations in more general terms. Using very similar language to that used in the First Phase Plan, the Second Phase Plan provides that:

Human rights education aims at developing an understanding of our common responsibility to make human rights a reality in every community and in society at large. In this sense, it contributes to the long-term prevention of human rights abuses and violent conflicts. ${ }^{45}$

Preventive measures can only be effective if there is an understanding of the causes of human rights violations. The Second Phase Plan recognizes this when stating that educational activities should encourage analysis of chronic causes of human rights problems, including, for example, poverty. ${ }^{46}$ Thus, the Second Phase Plan identifies HRE as a tool not only for preventing human rights violations, but also for addressing the underlying causes of such violations.

\footnotetext{
43 A/HRC/15/28, 27 July 2010.

44 Paragraph 41.

45 Paragraph 1.

46 Paragraph 9(c).
} 


\subsection{CONCLUSION}

There is no doubt that the drafters of the UDHR perceived HRE as an important tool in creating a culture where human rights are respected, and in preventing future human rights abuses. This chapter demonstrates that several bodies within the UN continue to see HRE in this way, and have articulated this view, albeit sometimes more clearly than others.

All of this suggests that the time is ripe for HRE to come to the forefront of international consciousness, and to fulfil its intended role as a preventive tool. This book aims to play a small part in facilitating this, by providing comprehensive and meaningful empirical research that exposes, warts and all, the way in which the UN has sought to advance HRE in the 60-plus years since it was first propounded by the drafters of the UDHR, and by suggesting how the UN might work more effectively in this area. 